\title{
Graphene Oxide (G0) Supported Palladium (Pd) Nanocomposites for Enhanced Hydrogenation
}

\author{
Dibya Ranjan Rout1, Pragyan Senapati2* ${ }^{*}$, Harekrushna Sutar1,3 ${ }^{\circledR}$, Deepak Chandra Sau4 ${ }^{(1)}$, \\ Rabiranjan Murmu ${ }^{3}$
}

\author{
${ }^{1}$ Chemical Engineering Department, Jadavpur University, Kolkata, India \\ ${ }^{2}$ Mechanical Engineering Department, ITER, SOA Deemed to Be University, Bhubaneswar, India \\ ${ }^{3}$ Chemical Engineering Department, Indira Gandhi Institute of Technology, Sarang, India \\ ${ }^{4}$ CSIR, National Metallugical Laboratory, Jamshedpur, India \\ Email: `pragyansenapati@soa.ac.in, h.k.sutar@gmail.com, dcsau@nmlindia.org
}

How to cite this paper: Rout, D.R., Senapati, P., Sutar, H., Sau, D.C. and Murmu, R. (2019) Graphene Oxide (GO) Supported Palladium (Pd) Nanocomposites for Enhanced Hydrogenation. Graphene, 8, 33-51. https://doi.org/10.4236/graphene.2019.83003

Received: July 2, 2019

Accepted: July 28, 2019

Published: July 31, 2019

Copyright (C) 2019 by author(s) and Scientific Research Publishing Inc. This work is licensed under the Creative Commons Attribution International License (CC BY 4.0).

http://creativecommons.org/licenses/by/4.0/

\begin{abstract}
The present study is an attempt to discover the hydrogen storage capacity of graphene oxide-Palladium (GO-Pd) nanocomposite through Benkeser reaction. A new route has been developed to adsorb hydrogen using GO-Pd as storage medium. Graphite is oxidised using improved Hummer's method (soft chemistry synthetic route) to produce graphene oxide (GO) nanoparticles. GO-Pd composite is synthesized by ultrasonication, chemical treatment with potassium tetrachloropalladate $\left(\mathrm{K}_{2} \mathrm{PdCl}_{4}\right)$ and overnight heat treatment. The prepared GO-Pd nanocomposite is hydrogenated by using lithium, ethylene diamine in argon atmosphere under ambient conditions. The hydrogenated graphene oxide-Palladium (H-GO-Pd) nanocomposites were characterized by scanning electron microscope (SEM), Fourier transform infrared spectra (FTIR) analysis, thermo gravimetric analysis (TGA) and X-ray diffractogram analysis. The FTIR analysis reports that hydrogen is adsorbed at three positions (ortho, meta and para) of graphene. The TGA analysis is used to understand the degradation behaviour of $\mathrm{H}-\mathrm{GO}-\mathrm{Pd}$ nanocomposite. It is to be noted that the degree of hydrogenation $(\mathrm{DH})$ or hydrogen storage of the prepared H-GO-Pd is 17.35 weight \%. Although it is not surprising, the $\mathrm{DH}$ is quite higher than the previously reported values. Thus graphene oxide supported Palladium nanocomposites is a definite resource for improved hydrogenation than the earlier disclosed materials using graphene.
\end{abstract}

\section{Keywords}

Graphene Oxide, Palladium, Hummers Method, Birch Method, Benkeser Reaction, Hydrogen Storage 


\section{Introduction}

Carbon exists as the most captivating element in the periodic table. It serves as the base of all known life on earth. The carbon atoms can be arranged into diverse allotropes, mainly including the well-known forms of graphite, diamond, fullerene, amorphous carbon, carbon nanotube and graphene in Figure 1. Different properties of graphene are sketched in Figure 2. Graphene has been extensively studied over one decade due to its superior properties. A single sheet of graphene is an atomic layer of $\mathrm{sp}^{2}$ hybridized carbon densely packed into a honeycomb pattern (hexagonal lattice), in which each atom forms a vertex with a $\mathrm{C}-\mathrm{C}$ distance of $0.142 \mathrm{~nm}$ in a fluctuated plane [1]. It represents a two-dimensional allotrope of carbon and is recognized as the first two-dimensional crystalline

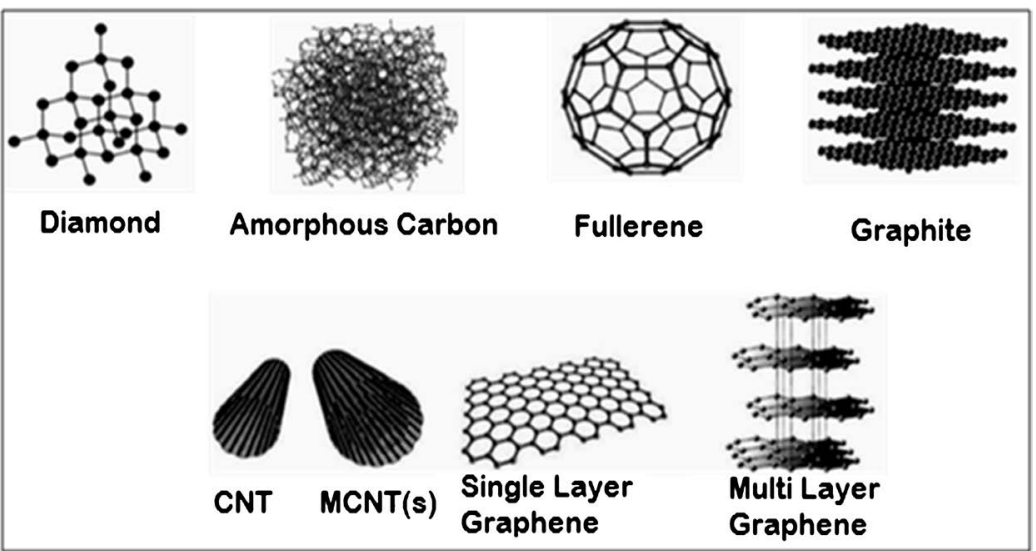

Figure 1. Allotropes of carbon [4].

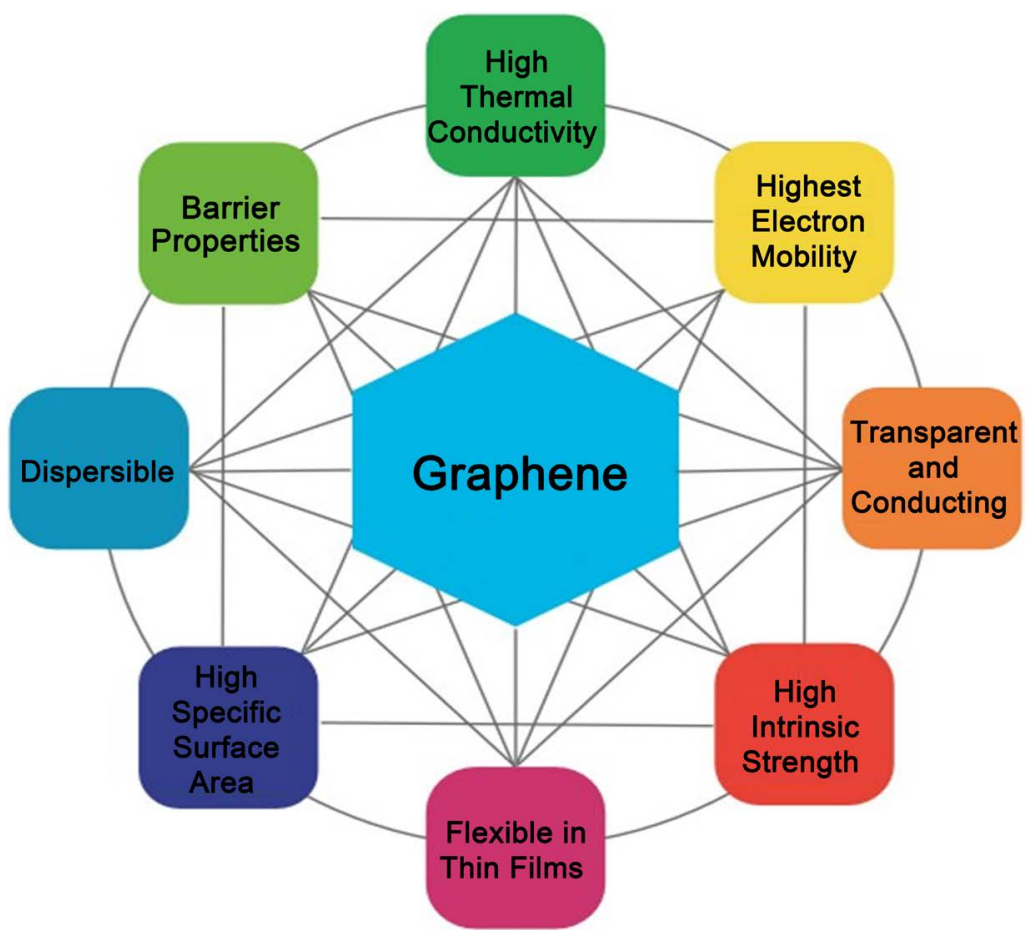

Figure 2. Schematic diagram of graphene properties. 
material. Layers of graphene stacked on top of each other form graphite, with an interplanar spacing of 0.335 nanometres. In particular, graphene is a good electrical conductor [2]. The electrical conductivity makes it rather promising for the design of electronic devices. The potential products include the field effect transistors, sensors, transparent conductive films and clean energy devices. Additionally, graphene is harder than diamond. Graphene can theoretically offer best volumetric hydrogen capacity among other carbon materials due to full coverage of material surface by adsorbent molecules [3].

The long term reliance of humanity on the energy solely derived from fossil fuels, has led to a number of challenges, including global warming followed by climate changes [4] [5]. This is due to the release of huge amounts of greenhouse gas $\mathrm{CO}_{2}$ because most of our energy requirement is derived from hydrocarbons such as petroleum and natural gas [6] [7] [8]. Unfortunately half of $\mathrm{CO}_{2}$ comes from combustion of hydrocarbons; therefore there is a need to replace fossil fuels with environmentally friendly and renewable energy carriers. Among all, Hydrogen is the most discussed and promising source of alternative fuel as compared to traditional fossil fuels, because hydrogen is abundant and has a higher gravimetric energy density $\left(120 \mathrm{~kJ} \cdot \mathrm{g}^{-1}\right)$ than gasoline, coal, and other carbon-rich fuels, scientists consider it as a promising candidate for replacing fossil fuels to power vehicles and a solution to the anticipated energy crisis [9], it can also be used efficiently in proton exchange membrane fuel cells (PEMFC) and combustion engines [10]. For example four kilograms of hydrogen are needed for an electric car equipped with fuel cell to provide distance range of $400 \mathrm{~km}$ without refilling, the distance typical for a small car with combustion engine. However, unacceptably large tank with the volume of 225 litres is needed to store 4 kilograms of hydrogen under 200 bar. That is 4 times larger than the tanks used to store petrol in small cars. Storing the hydrogen in liquid form improves energy density but requires using very low temperature $\left(-243^{\circ} \mathrm{K}\right)$ [11]. The liquefaction is energy consuming and technically complicated whereas the evaporation of hydrogen from the storage vessels creates risk of explosions. Therefore, the production, storage, and delivery of hydrogen are of great importance to the widespread use of hydrogen. Developing secure, close-packed, dependable, and cost-effective hydrogen storage technologies turns into one of the most technical challenges in the fundamental and applied research for hydrogen economy. The hydrogen used for the fuel cell could be stored as compressed or liquefied gas, a chemical hydride, a metal hydride or in other solid adsorbent materials. Among them, hydrogen storage in solids is the most promising approach to meet the targets, with potential materials of microporous sorbents and metals being considered. The atomic or molecular hydrogen bound firmly with other elements in a solid material may enable the storage of hydrogen in larger quantities and smaller volumes at practical conditions [12] [13]. Many scientists from various part of the world support for the use of carbon nanomaterials as effective hydrogen storage media. Hydrogen storage in high surface area carbon nanomaterials such as 
graphene [14] [15] [16] [17] based materials, carbon nanotubes [18] [19], activated carbon has been well investigated. Among these carbon nanomaterials, graphene, the new member of carbon family, has attracted great intense interest for its unique and highly desirable electrochemical, mechanical, and electrical properties such as a large theoretical specific surface area $\left(2630 \mathrm{~m}^{2} \cdot \mathrm{g}^{-1}\right)$ [20] [21], high values of Young's modulus, excellent thermal conductivity $\left(\sim 5000 \mathrm{~W} \cdot \mathrm{m}^{-1} \cdot \mathrm{s}^{-1}\right)$ [21] [22], and outstanding resistance to gas permeation [23]. In spite of that, pure graphene cannot secure hydrogen at ambient conditions. To overcome these problems, efforts have been made to combine metals and graphene oxide for hydrogen storage, because graphene oxide (GO), the functionalized graphene with oxygen-containing chemical groups, has recently attracted resurgent interests because of its superior properties such as large surface area, mechanical stability, tuneable electrical and optical properties. Moreover, the surface functional groups of hydroxyl, epoxy and carboxyl make GO an excellent candidate in coordinating with other materials or molecules [24]. Such combined system should enable the dispersion of metal and allow functionalization of the graphene and, as a result, should enhance the gravimetric and volumetric storage densities to achieve the similar performance and cost with the gasoline fuel systems. Among the metals, Pd particles favourably attract hydrogen at ambient conditions and produce a low activation energy barrier to dissociate hydrogen. Typically, in the absence of protective agents, metallic nanoparticles (NPs) tend to aggregate due to attractive molecular Vander Waals forces [25] [26]. To overcome this aggregation, and toward improving their morphology and catalytic activity, they are commonly deposited on solid materials that possess larger surface areas. Therefore, the present work aims at identifying the new materials $\mathrm{Pd} /$ graphene oxide nanocomposites with hydrogen storage abilities.

Hydrogen sorption and storage may be augmented at room temperature by a phenomenon called the "spill over effect", which is defined as the chemical dissociation of hydrogen molecules on metallic NPs in the form of atomic hydrogen, and the subsequent migration of these hydrogen atoms onto adjacent surfaces of the adsorbate via surface diffusion [26] [27] [28].

However, chemisorption is an alternative way to enhance the extent of storage. In order to chemically adsorb hydrogen, different methods have been implemented to hydrogenate the graphene including Birch reaction [21] [29] [30], high pressure hydrogenation [31], H-plasma procedure, polyamine hydrogenation and Benkeser reaction. Birch reaction is a low-temperature chemical hydrogenation process involving liquid ammonia, which is very difficult to handle [21]. Hydrogenation of graphene oxide-Palladium nanocomposite by Benkeser reaction which is the modified version of Birch reaction is of great importance not only it can de bundle and disperse GO-Pd in organic solvents, but also the hydrogenated GO-Pd with covalent $\mathrm{C}-\mathrm{H}$ bonds are proved as a stable form of hydrogen storage at room temperature. Several studies [32] [33] [34] relating graphene based nanoparticles for storage of hydrogen are performed across the 
globe for the last few years [35]. An effort has been built to identify some of the main facts, which may have some impact to the work and morphological characterization of these materials for their hydrogen storage property [36] [37].

Herein, we report the hydrogenation of graphene oxide-Palladium nanocomposite using lithium in ethylene diamine by Benkeser reaction method [38] [39], which provides a convenient, mild and possibly scalable way to obtain the hydrogenated GO-Pd compared with the traditional Birch reduction, which is used to store hydrogen on multiwall carbon nanotube (MWCNT). Benkeser reaction is superior as compared to Birch reaction because it occurs under atmospheric condition that is at room temperature and pressure as compared to Birch reaction which occurs at low temperature and a long time for the evaporation of the liquid ammonia. In our experiment, tert-Butanol was used as the proton source.

The as prepared GO-Pd and hydrogenated GO-Pd nanocomposites were characterized by Scanning Electron Microscopy (SEM), X-Ray Diffraction (XRD), Fourier Transform Infrared Spectroscopy (FTIR), BET surface area analyser and thermogravimetric analysis (TGA).

\section{Materials and Methods}

\subsection{Preparation of Graphene Oxide (GO)}

The following materials are used for preparing GO using improved Hummer's Method in order to get the high $\mathrm{C} / \mathrm{O}$ ratio.

- Graphite flakes-(Luba Cheme, extra pure 99.5\%, $50 \mu \mathrm{m}$ average sizes, bulk density $20-30 \mathrm{gm} / 100 \mathrm{ml}$ ).

- Sulphuric Acid $\left(\mathrm{H}_{2} \mathrm{SO}_{4}\right)$ - (MERCK, 98\% concentration, density $\left.1.84 \mathrm{Kg} / \mathrm{L}\right)$.

- Phosphoric Acid $\left(\mathrm{H}_{3} \mathrm{PO}_{4}\right)$-(MERCK, $88 \%$ concentration, density $1.75 \mathrm{Kg} / \mathrm{L}$ ).

- Potassium Permanganate $\left(\mathrm{KMnO}_{4}\right)$-(MERCK, $99 \%$ purity).

- Hydrogen Peroxide $\left(\mathrm{H}_{2} \mathrm{O}_{2}\right)$-(MERCK, $30 \%$ concentration).

- Hydrochloric Acid (HCl)-(MERCK-35\% concentration, density $1.18 \mathrm{Kg} / \mathrm{L})$.

- Ethanol $\left(\mathrm{C}_{2} \mathrm{H}_{5} \mathrm{OH}\right)$ - (MERCK, $99.9 \%$ purity, density $\left.0.79 \mathrm{Kg} / \mathrm{L}\right)$.

- Distilled water.

The steps involved in this method are:

- $360 \mathrm{ml} \mathrm{H}_{2} \mathrm{SO}_{4}$ (98\%) and $40 \mathrm{ml} \mathrm{H}_{3} \mathrm{PO}_{4}$ (88\%) were taken in a beaker (Volume ratio of 9:1).

- Graphite powder was added into the acid mixture and stirred for 15 minutes with the help of a hot plate having rpm of 600 - 650 .

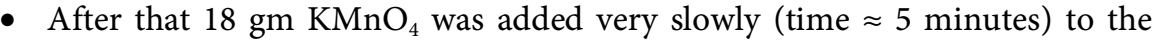
above mixture by stirring. This reaction is exothermic in nature so the temperature was seen to increase abruptly to $60^{\circ} \mathrm{C}$. So addition of $\mathrm{KMnO}_{4}$ was done very cautiously.

- The above mixture was stirred for $15 \mathrm{~min}$ and temperature was noted. When temperature decreased to $50^{\circ} \mathrm{C}$, a hot plate was used to maintain the mixture temperature $55^{\circ} \mathrm{C}-60^{\circ} \mathrm{C}$ for 7 - 8 hours.

- The said temperature should be maintained throughout the reaction, after 
completion of reaction $400 \mathrm{ml}$ cold water $\left(10^{\circ} \mathrm{C}-15^{\circ} \mathrm{C}\right)$ was added into the mixture.

- Then $6 \mathrm{ml} \mathrm{H}_{2} \mathrm{O}_{2}$ (30\%) was added and the mixture was kept on ice bath overnight.

- Next day yellowish coloured GO was precipitated. The clear solvent was discarded slowly by siphon.

- In order to wash the $\mathrm{GO}$ slurry, $400 \mathrm{ml} \mathrm{HCl}$ solution (35\%) was added and the mixture was allowed for GO to precipitate.

- After 3 hours GO further precipitated, and was separated by siphon.

- After successive stages of washing with $\mathrm{HCl}$ solution, $200 \mathrm{ml}$ of ethanol was added for the coagulation of the material.

- After 4 hours the clear liquid was separated and thick GO slurry was taken.

- Then GO slurry was filtered by filter paper.

- The wet GO was scraped from filter paper and dried in a vacuum oven at $90^{\circ} \mathrm{C}$ for 4 hours.

- Thus the dried GO was cooled and kept in sample bottle.

\subsection{Preparation of GO-Pd Nanoparticles}

The steps involved during the preparation of GO-Pd nanocomposite by Birch method are listed out bellow

- In a beaker $35 \mathrm{mg} \mathrm{GO}$ was taken, after that $40 \mathrm{ml}$ distilled water was added to it. Then the mixture was sonicated for 1 hour.

- After that $\mathrm{K}_{2} \mathrm{PdCl}_{4}(20 \mathrm{mg})$ was taken in a small beaker and $10 \mathrm{ml}$ distilled water was added to it. The mixture was added to the previous mixture and sonicated for 1 - 1.5 hour.

- $1 \mathrm{ml} \mathrm{NH}_{4} \mathrm{OH}$ was added drop wise to the mixture and stirred for 30 minutes.

- Then the solution was put into a $50 \mathrm{ml}$ teflon autoclave at a temperature of $140^{\circ} \mathrm{C}$ for 24 hour to form dry GO-Pd nanocomposite.

\subsection{Preparation of Hydrogenated GO-Pd}

- Hydrogenation of GO-Pd was carried out by using Benkeser reaction [21]. The reaction was carried out under argon atmosphere.

- Sixty milligrams GO-Pd and $80 \mathrm{ml}$ ethylene diamine $\left(\mathrm{C}_{2} \mathrm{H}_{8} \mathrm{~N}_{2}, 99 \%\right.$ purity) were mixed in a flask. The mixture was stirred for $20 \mathrm{~min}$ under argon atmosphere in a closed flask.

- Then, $200 \mathrm{mg}$ lithium (Luba Chemical, 99\% purity) pieces were added to it, and the colour changed to blue. After that, $5 \mathrm{ml}$, tert-Butanol (98\% purity) was added drop wise to the mixture and stirred for 6 hour at room temperature.

- The resulting dark solution was diluted by adding $60 \mathrm{ml}$ ethanol. Then, it was filtered by Whatman filter paper.

- Filtered hydrogenated GO-Pd (H-GO-Pd) was washed with ethanol, acetone, and deionized water. The product was dried in a vacuum oven at $80^{\circ} \mathrm{C}$ overnight to obtain hydrogen functionalized GO-Pd composite. 


\subsection{Characterization of Hydrogenated GO-Pd Composite}

X-ray diffraction (XRD, BRUKER D8 Advance) spectras were obtained by using $\mathrm{Cu}-\mathrm{K} \alpha$ radiation $\left(1 / 41.5418^{\circ} \mathrm{A}\right)$ in the range of $5^{\circ}-90^{\circ}$ with a scanning speed of $5 \mathrm{~min}^{-1}$. Scanning Electron microscopy (SEM) images were obtained using A JEOL JEM 2100 (JEOL KOREA LTD., Seoul, Korea) at voltage of 200 kV. Fourier transformation infrared spectra were recorded on an IR Affinity-1 and IR Prestige-21 FTIR Spectrometer (Shimadzu, Chiyoda-Ku, Tokyo, Japan). The samples were compressed into a pellet with $\mathrm{KBr}$. The surface structure parameters were calculated from the $\mathrm{N}_{2}$ adsorption/desorption isotherms, which were obtained using an automated surface area analyser [5]. A standard BET sample holder was used to hold the GO-Pd and hydrogenated GO-Pd nanocomposites. Total weight of the sample during analysis was $0.04 \mathrm{gm}$. The samples were first out gassed at $150^{\circ} \mathrm{C}$ for 2.5 hours under vacuum and then the isotherm is measured over the relative pressure $\left(\mathrm{P} / \mathrm{P}_{0}\right)$. Thermogravimetric analyses (TGA) were carried out on Pyris Diamond TG/ DTA (Perkin Elmer, Singapore). The sample was heated from $32^{\circ} \mathrm{C}$ to $1000^{\circ} \mathrm{C}$ with a rate of heating $15^{\circ} \mathrm{C} /$ min under nitrogen atmosphere (circulation rate $150 \mathrm{ml} / \mathrm{min}$ ). Platinum crucible was used with alpha alumina powder as reference.

\section{Results and Discussions}

\subsection{Analysis of XRD}

The crystalline structure of synthesized GO, GO-Pd, and hydrogenated GO-Pd were studied by analysing XRD patterns. The synthesized GO has a sharp intensity peak at $2 \theta$ value of $10.4^{\circ}$ corresponding to (001) plane as shown in Figure 3. The broadness of peak at $2 \theta$ value of $26.8^{\circ}$ for both GO-Pd and hydrogenated GO-Pd in Figure 4 and Figure 5 is due to the increased disorder of the layers

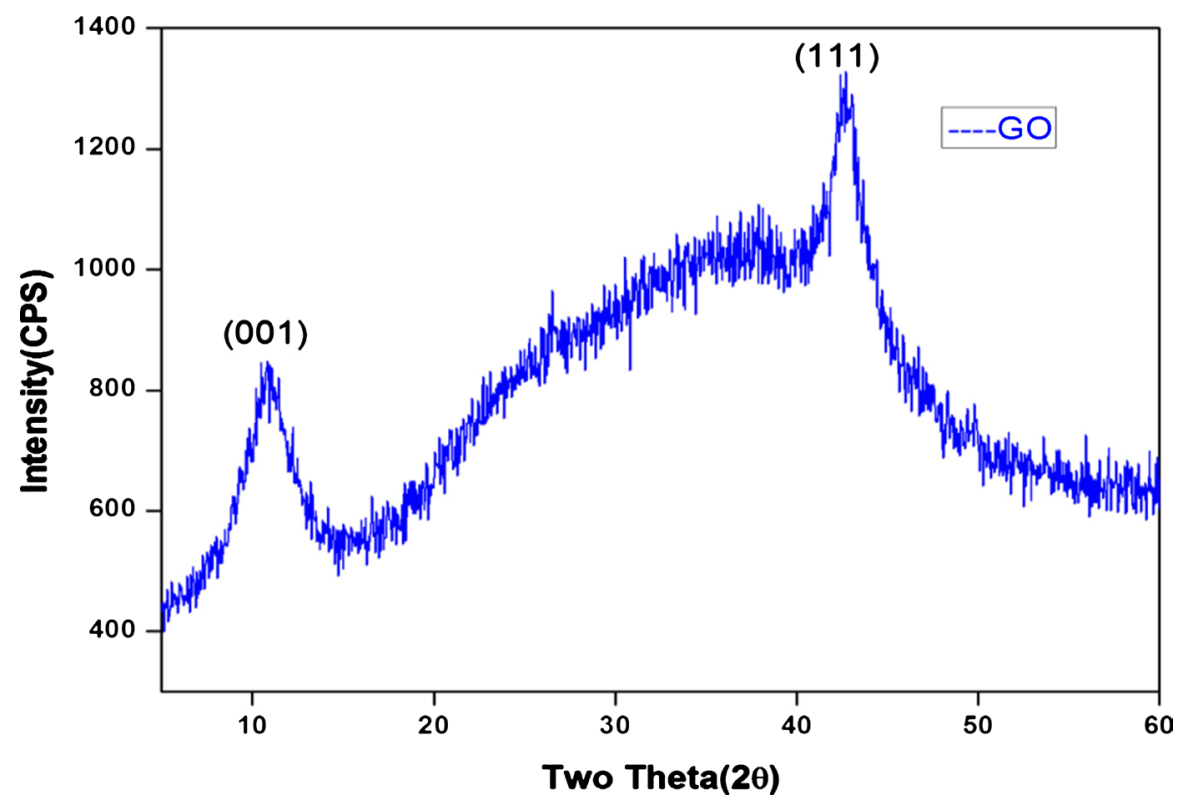

Figure 3. XRD pattern of GO. 


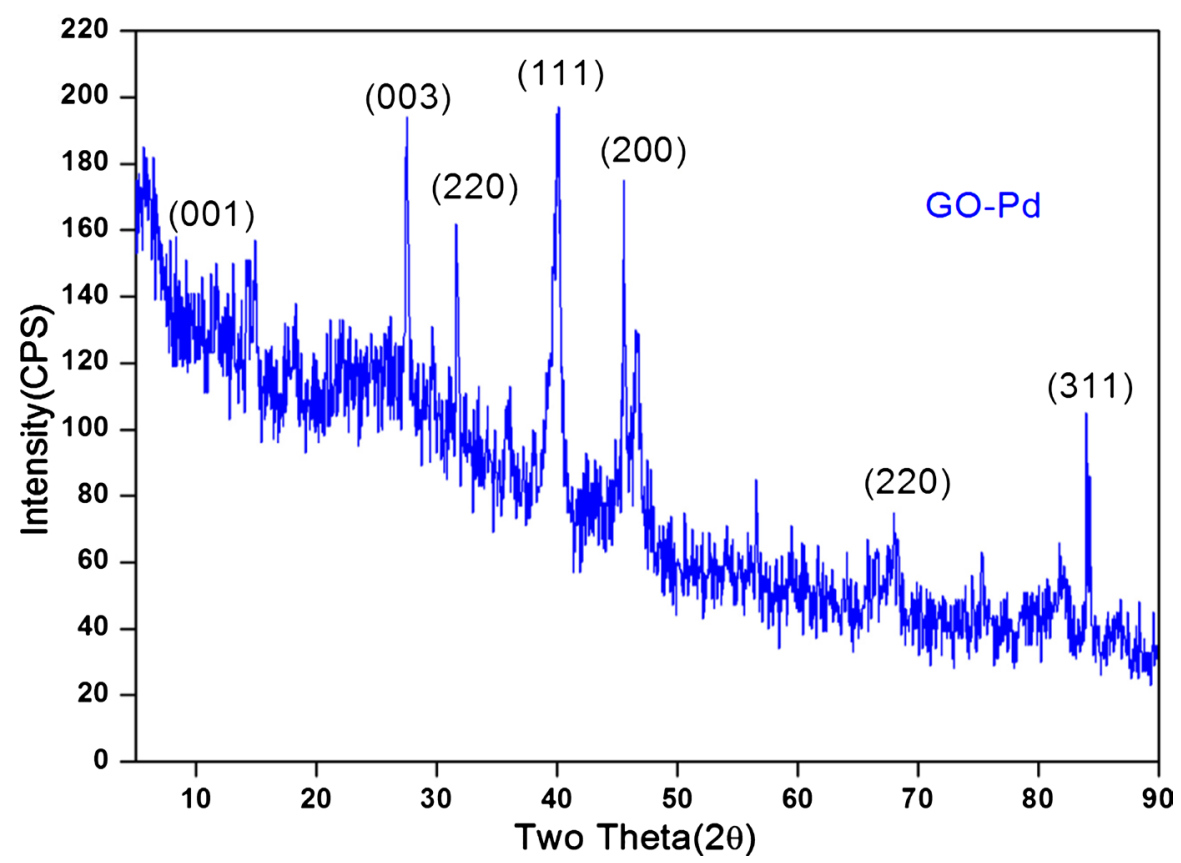

Figure 4. XRD pattern of GO-Pd.

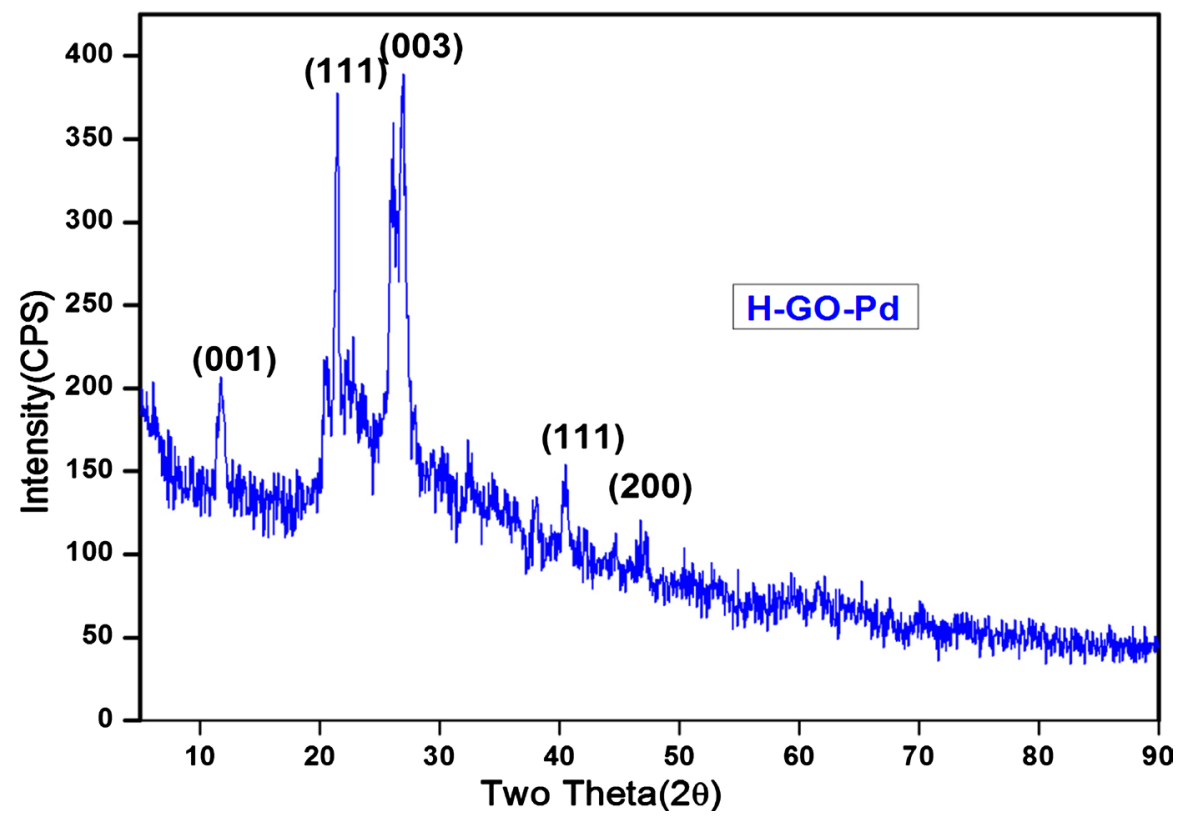

Figure 5. XRD pattern of H-GO-Pd.

present in the graphene oxide. In GO, GO-Pd and hydrogenated GO-Pd samples, the above-mentioned peaks are preserved in the same manner along with the prominent Pd peaks. This is an indication of the successful immobilization of Pd nanoparticles over GO-Pd matrix. The diffraction pattern of GO-Pd exhibited strong crystalline peak at $2 \theta$ value of $40.3,46.7,68.2$ and $83.75^{\circ}$ corresponding to the (111), (200), (220) and (311) planes of a face centred cubic structure of crystalline $\mathrm{Pd}$ and is in good agreement with the available literature [40]. Peak at $40.3^{\circ}$ (111) for both Figure 4 and Figure 5 clearly indicates the 
nanostructured nature of the palladium particles. XRD pattern of hydrogenated GO-Pd is shown in Figure 5 and the peak at around $10.5^{\circ}$ (001) confirms the presence of GO on the nanoparticles. The peak at $22.5^{\circ}$ (111) shows the presence of lithium. The strongest peak appeared at $2 \theta=40.44^{\circ}$, showing that the Pd nanoparticles were embedded into the graphene sheets in the dominant (111) oriented plane. As evident from the XRD profile the peaks are gradually shortened as compared to the XRD profile of GO-Pd nanoparticles. So it shows the Pd particles are adsorbed on the surface of GO.

\subsection{Analysis of FTIR}

The decoration of the surface of the graphene sheets by palladium nanoparticles was discussed by FTIR spectroscopy and also FTIR gives the idea about the chemical bonding of the samples. Figure 6 shows the FTIR spectra of GO-Pd and hydrogenated GO-Pd. It clearly shows the attachment of different functional groups to the GO-Pd nanoparticles after hydrogenation. FTIR spectrum revealed that the GO-Pd nanoparticles contain several functional groups like; $-\mathrm{OH}$ bending at $3436 \mathrm{~cm}^{-1}, \mathrm{C}=\mathrm{C}\left(1370 \mathrm{~cm}^{-1}\right)$ and $\mathrm{C}=\mathrm{O}$ carbonyl stretching at 1630 $\mathrm{cm}^{-1}$ [41]. Therefore it has a strong tendency to readily interact with metal ions by hydroxyl and carboxyl group. A peak can be seen around at $3436 \mathrm{~cm}^{-1}$ which shows the stretching mode of $\mathrm{O}-\mathrm{H}$, the peak at wave number $3600 \mathrm{~cm}^{-1}$ on hydrogenated GO-Pd as described as the O-H stretching of hydroxyl group that may come from the adsorbed solvents like ethanol and water. On GO-Pd the peaks at $2923 \mathrm{~cm}^{-1}$ and $2859 \mathrm{~cm}^{-1}$ are due to asymmetric and symmetric stretching of C-H bonds. The peak at $1631 \mathrm{~cm}^{-1}$ in $\mathrm{H}-\mathrm{GO}-\mathrm{Pd}$ can be attributed to stretching modes of $-\mathrm{CO}$ group, the peaks at the wave numbers $1395 \mathrm{~cm}^{-1}$ and $1475 \mathrm{~cm}^{-1}$ indicate the aromatic $\mathrm{C}=\mathrm{C}$ stretching. Fourier transformation infrared

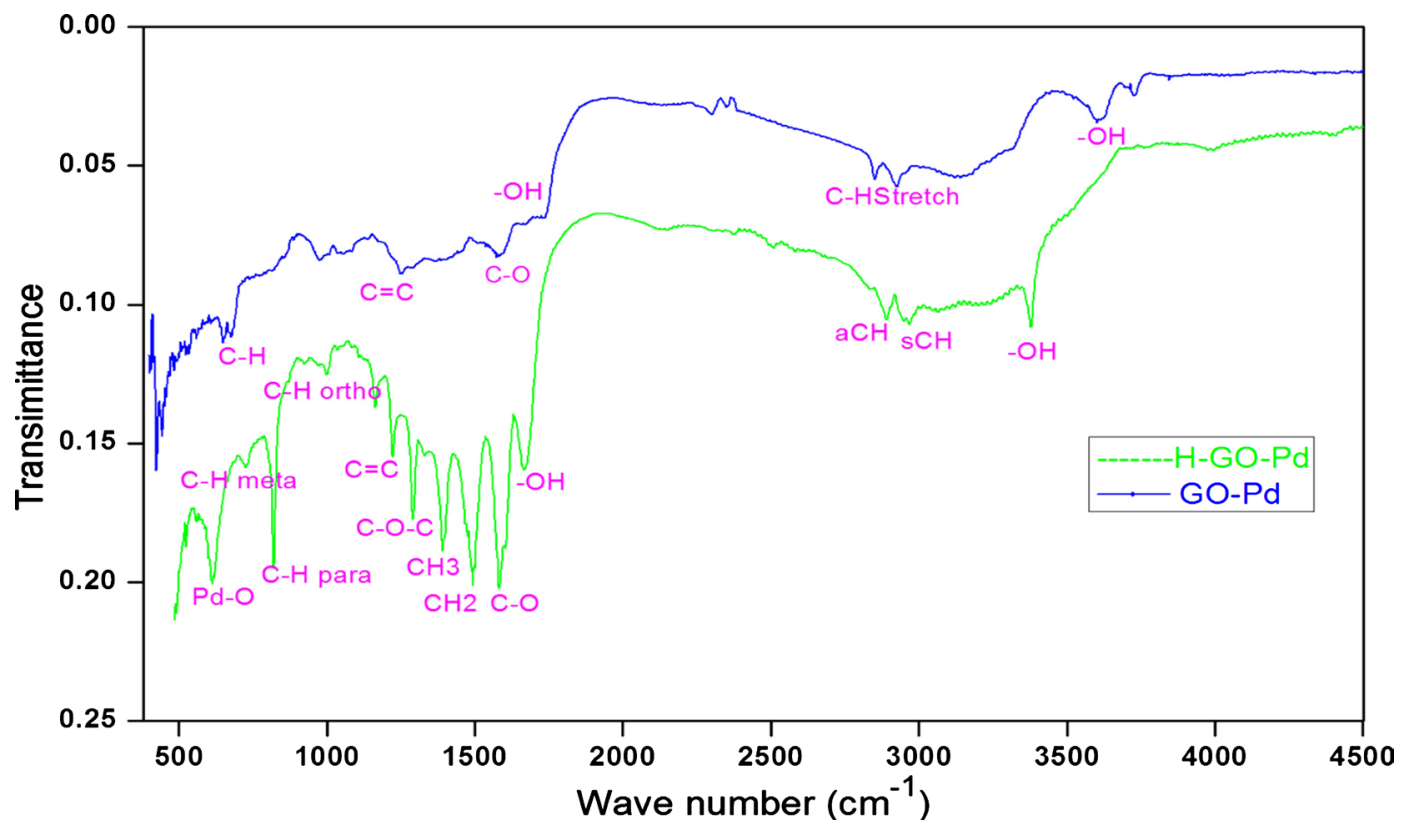

Figure 6. FTIR spectra of GO-Pd and hydrogenated GO-Pd. 
spectroscopy of hydrogenated GO-Pd shows different aromatic $\mathrm{sp}^{3}(\mathrm{C}-\mathrm{H})$ stretching at ortho, meta and para positions. Peak at $824 \mathrm{~cm}^{-1}$ wave number is responsible for $\mathrm{C}-\mathrm{H}$ stretching for para position, peak at $1002 \mathrm{~cm}^{-1}$ designates $\mathrm{C}-\mathrm{H}$ bond in ortho position and $729 \mathrm{~cm}^{-1}$ peak is the signature of $\mathrm{C}-\mathrm{H}$ stretching in meta position. It can be observed from FTIR analysis that hydrogen adsorption occurred at all the ortho, meta, and para positions of aromatic graphene. A peak at $621 \mathrm{~cm}^{-1}$ was signified the formation of Pd-O bond. It is well recognized that the GO-Pd bonding can be formed through some physi$\mathrm{cal} /$ chemical interactions such as Vander Waals force, H-bonding and other bonds. $\mathrm{Pd}$ atoms may possibly react with the $-\mathrm{OH}$ and $-\mathrm{COOH}$ groups on the functionalized GO and thus the bonding $\mathrm{C}-\mathrm{O}-\mathrm{Pd}$ or $\mathrm{O}=\mathrm{C}-\mathrm{O}-\mathrm{Pd}$ might form through a dehydration reaction.

\subsection{BET Surface Area Analysis}

Surface areas are commonly reported as BET surface areas and pore size distribution of GO-Pd and hydrogenated GO-Pd samples are obtained by applying the theory of Brunauer, Emmett, and Teller. Nitrogen adsorption isotherms measured at $77^{\circ} \mathrm{K}$ are shown in the Figure 7. Nitrogen at $77^{\circ} \mathrm{K}$ is considered to be a standard adsorbent for surface area and pore size analysis. The isotherms shown in Figure 7 follows type-IV curve which indicates the presence of mesoporous material in these samples. This type of isotherm was observed for all of the samples and at approximately $P / P_{0} \sim 0.65$, there is a hysteresis occurred that indicates the presence of small mesopores in the prepared nanocomposites [42]. The "C" parameter is a measure of the strength of the interaction of the adsorbate $\left(\mathrm{N}_{2}\right)$ with the surface and the higher the $\mathrm{C}$ parameter, the sharper the "knee point" in the early part of the isotherm at low $P / P_{0}$ [43] [44]. The value of

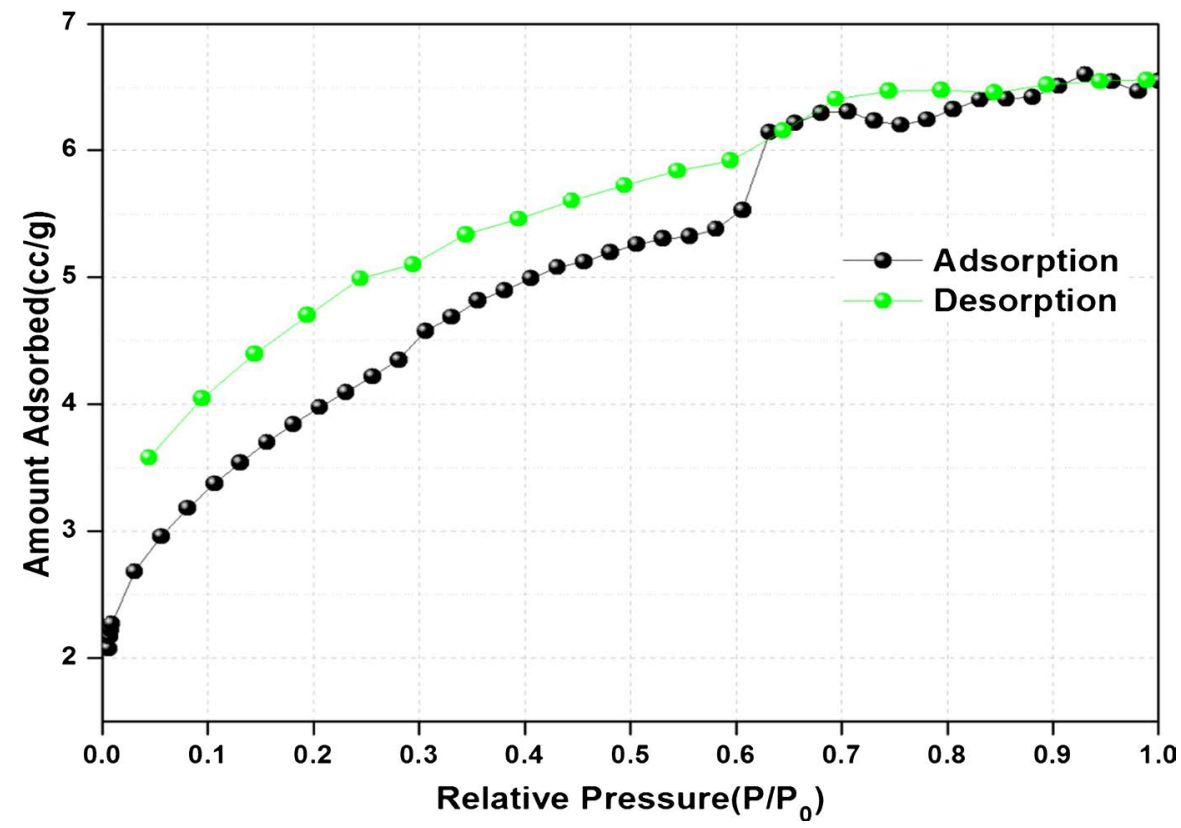

Figure 7. $\mathrm{N}_{2}$ adsorption desorption isotherm of hydrogenated GO-Pd at $77^{\circ} \mathrm{K}$. 
$\mathrm{C}$ for Nitrogen adsorption at $77^{\circ} \mathrm{K}$ for hydrogenated GO-Pd is 128.502 .

The BET plot of GO-Pd and hydrogenated GO-Pd are shown in the Figure 8 and Figure 9 and the distribution indicates the presence of mesopores (2 - 50 $\mathrm{nm}$ ), which makes the material as a unique gas adsorbing medium. GO-Pd sample has less mesopores and smaller pore volume, because some mesopores were blocked with Pd or other chemical reactions in the process of Pd-NPs decoration and the subsequent reduction. Because of this reason, the BET surface area of hydrogenated GO-Pd is $14.037 \mathrm{~m}^{2} / \mathrm{g}$ and it is less compared to GO-Pd surface

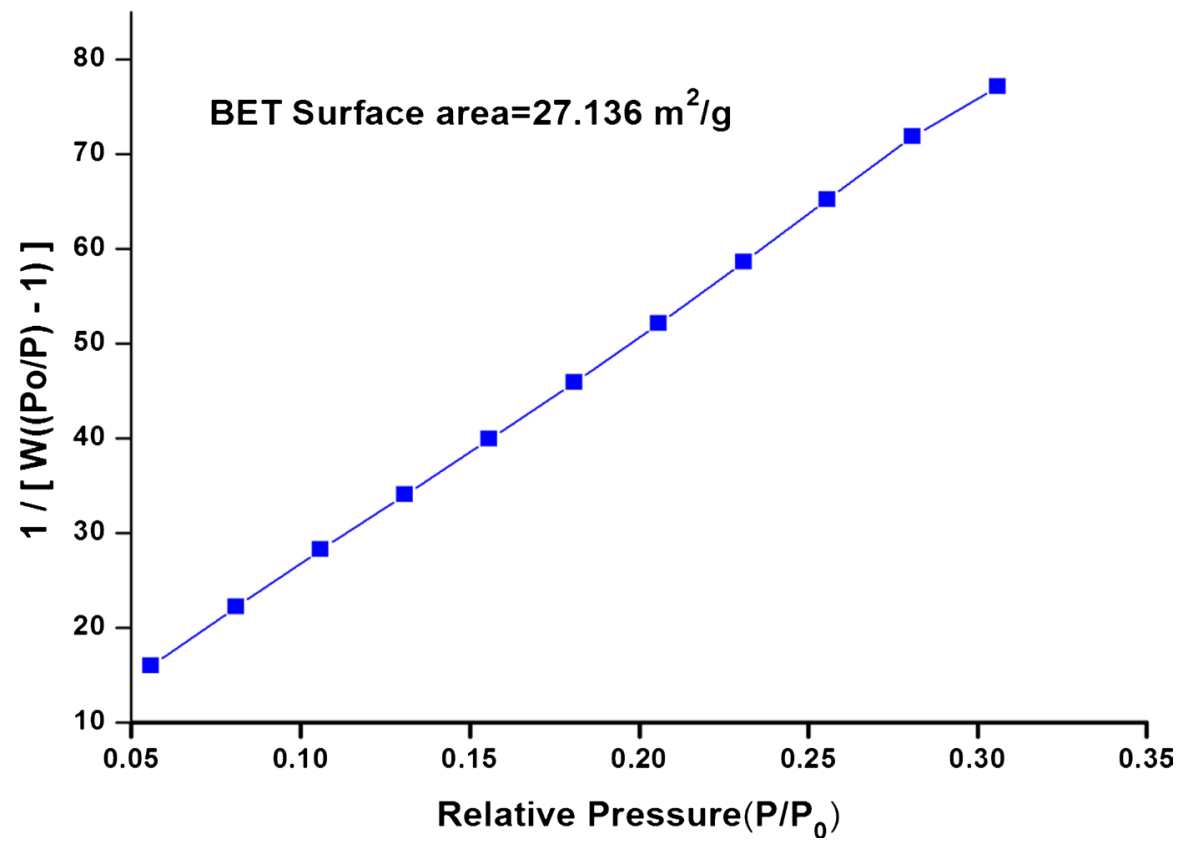

Figure 8. BET plot in the relative pressure range of $0.05-0.35$ for GO-Pd.

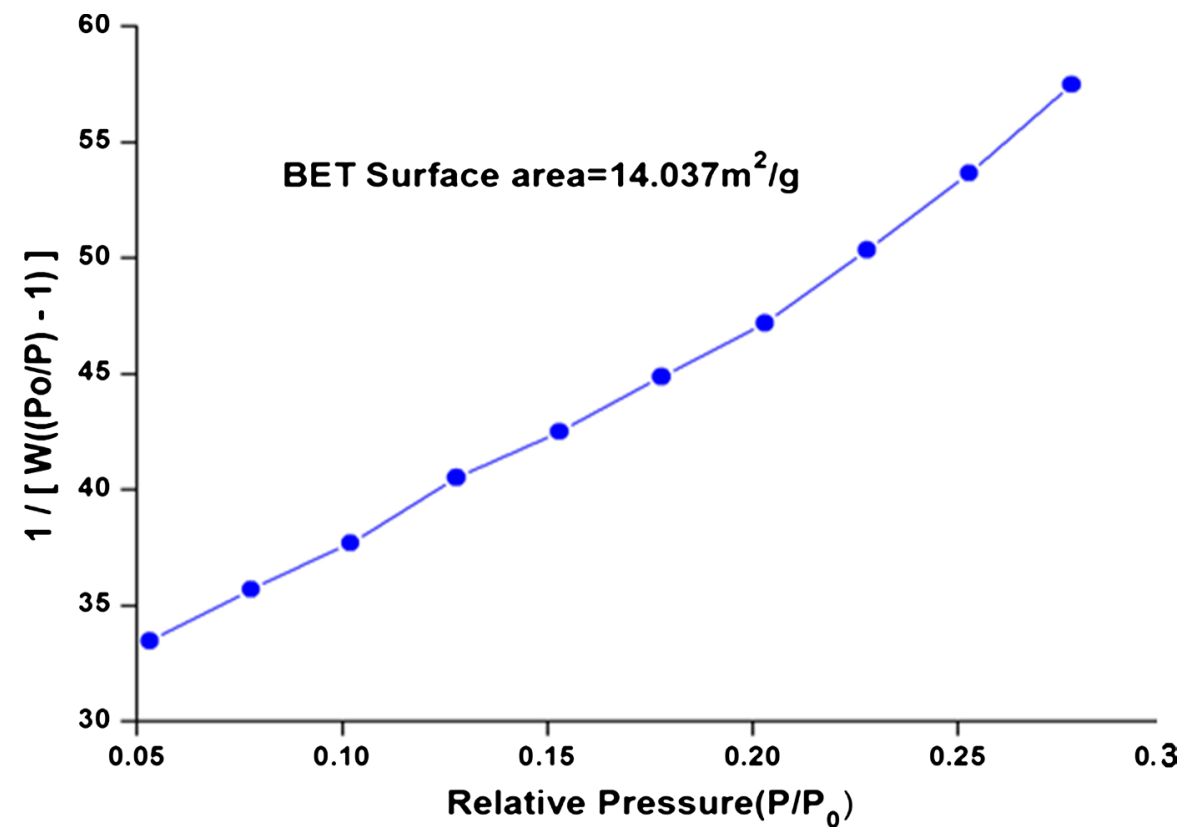

Figure 9. BET plot in the relative pressure range of 0.05 - 0.3 for hydrogenated GO-Pd. 
area which is $27.136 \mathrm{~m}^{2} / \mathrm{g}$. In Figure 10 and Figure 11 which is the pore size distribution of GO-Pd and hydrogenated GO-Pd, we have found from Barrett-Joyner-Halenda $(\mathrm{BJH})$ analysis that the pore volume of $\mathrm{GO}-\mathrm{Pd}$ is $0.023 \mathrm{cc} / \mathrm{g}$ as compared to $0.009 \mathrm{cc} / \mathrm{g}$ for hydrogenated GO-Pd. This contraction of pore volume indicates that hydrogen is filled in the pore after hydrogenation of GO-Pd nanoparticles. Hydrogen isotherms at $77^{\circ} \mathrm{K}$ show that capacities at very low temperature are associated with the surface area of the materials [45]. The activity of the palladium at $77^{\circ} \mathrm{K}$ is very weak because the kinetics of the adsorption process is extremely slow, and thus, the total capacity is mainly due to the

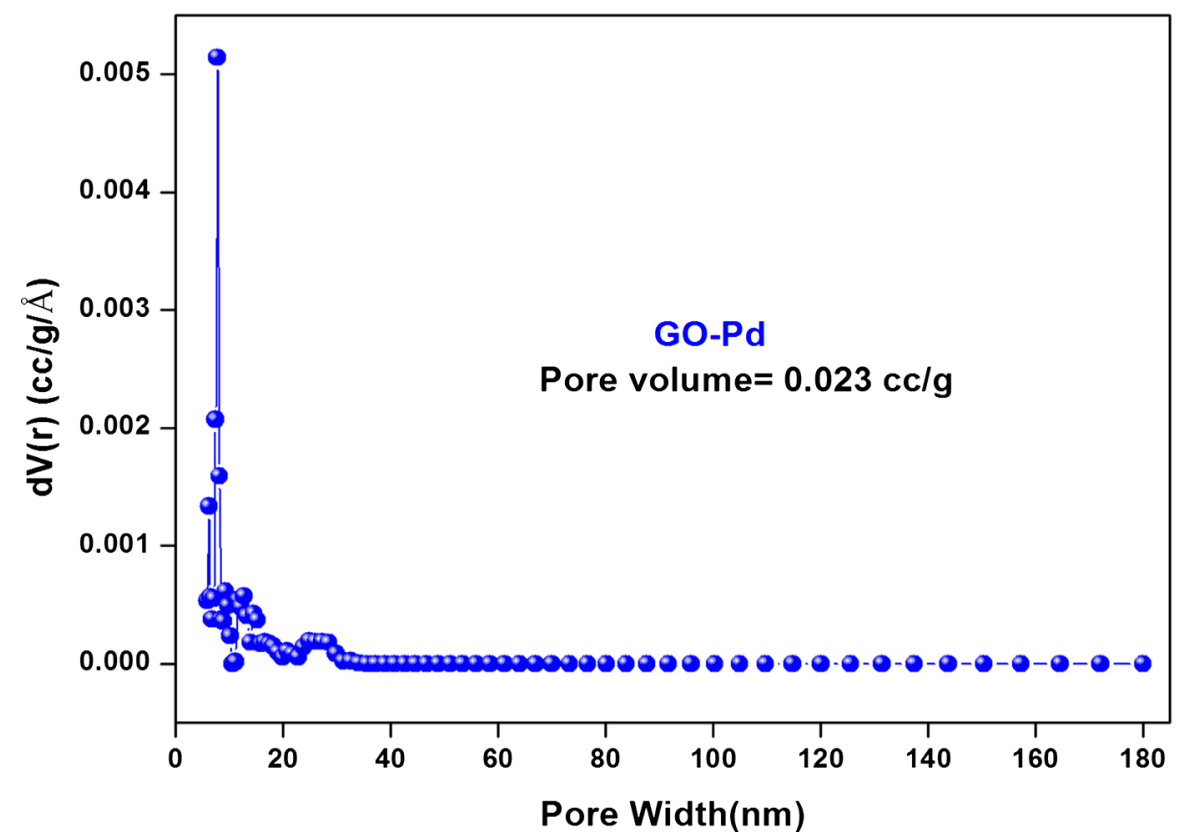

Figure 10. The pore size distribution (PSD) of GO-Pd.

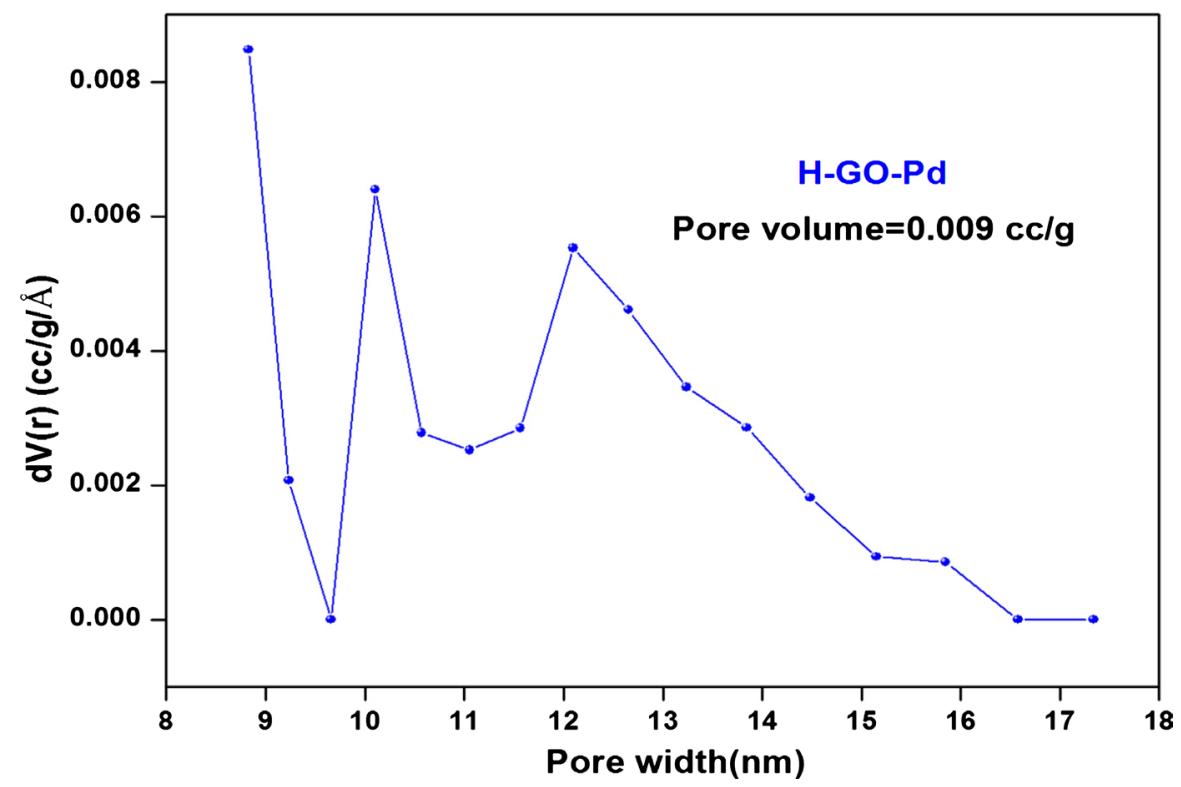

Figure 11. The pore size distribution (PSD) of hydrogenated GO-Pd. 
physical adsorption. The adsorption of hydrogen in the palladium structure is a quite complicated process that involves, first, dissolution of hydrogen in palladium and, second, formation of the palladium hydride [9] [45]. As the temperature increases, physical adsorption becomes weaker and the activity of palladium increases because the accommodation of hydrogen in the palladium crystalline network becomes faster.

\subsection{Scanning Electron Microscopy (SEM) Analysis}

For analysing the morphological characteristics of the composite we have done SEM characterization of samples. Figure 12 shows SEM images of GO-Pd and hydrogenated GO-Pd. The quality of dispersion of Pd particles in the graphene matrix significantly influences the hydrogen storage in the nanocomposite [46]. We optimized the distribution of particles, and Figure 12 exhibits the morphologies of the Pd/graphene oxide nanocomposites. Figure 12 shows uniform distribution of palladium particles on graphene oxide sheets and it signifies that palladium is uniformly mixed and spread across the graphene oxide. But after hydrogenation the morphology of GO-Pd nanoparticles are changed and the distribution of palladium is not uniform on the surface of graphene oxide sheet because palladium forms a cluster form with graphene oxide. The significant decrease of the Pd particle size in the nanocomposite could be related to an enhanced dispersion and lower mobility of Pd particles in the graphene substrate [21] [37] [46]. The particles could have bonded to the edges, defects, and functional groups on the surface of graphene. This interaction may have further stabilized the Pd nanoparticles and effectively prevented the particle aggregation on the graphene surface.

\subsection{Estimation of Extent of Hydrogen Storage from TGA Analysis}

Thermogravimetric analysis gives the details about this thermal instability of the

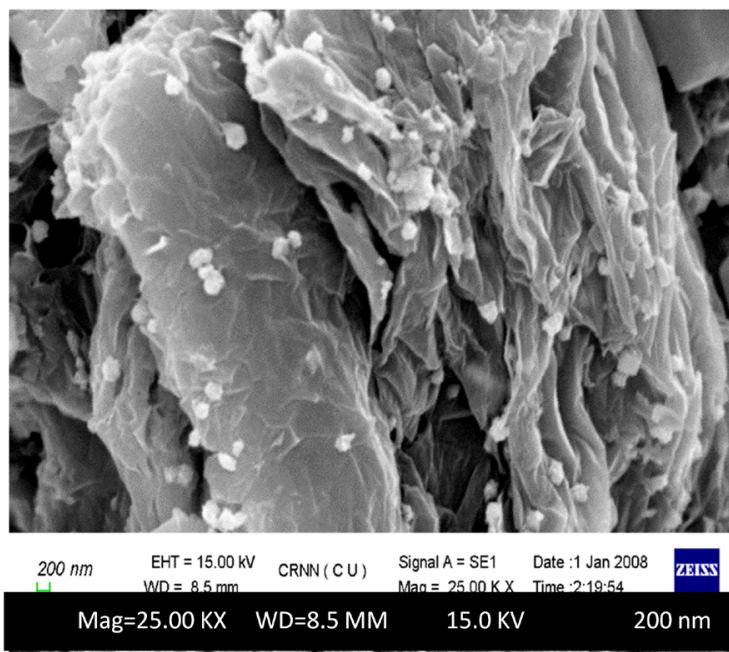

(a)

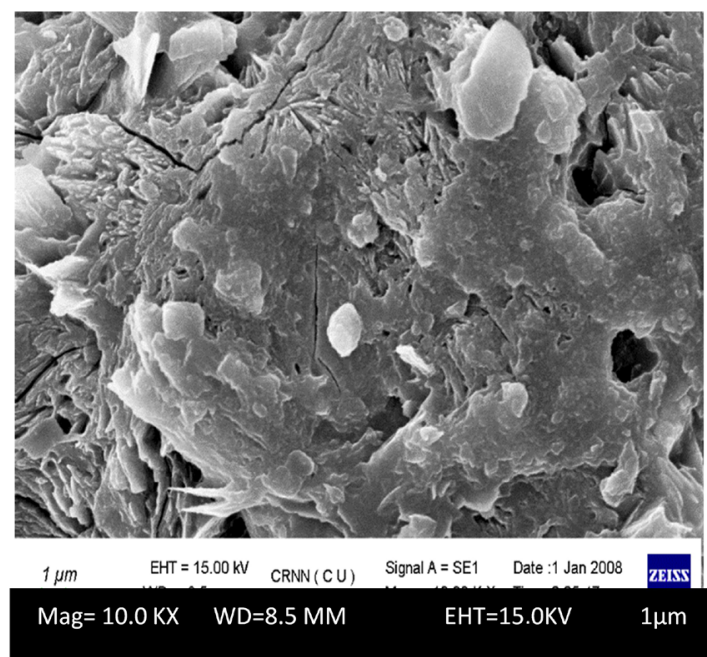

(b)

Figure 12. SEM image of (a) GO-Pd and (b) hydrogenated GO-Pd. 
chemical bonding. TGA is the useful tool to estimate the amount of functional groups attached to the graphene [21]. Figure 13 shows the TGA curves of GO-Pd and hydrogenated GO-Pd.

In Figure 13 we have shown that the reduction of wt\% occurs with increasing temperature. For both GO-Pd and hydrogenated GO-Pd mass reduction occurs from temperature of $20^{\circ} \mathrm{C}$. As boiling point of ammonia solution is $24.7^{\circ} \mathrm{C}$ the reduction starts below this temperature for both GO-Pd and hydrogenated GO-Pd. For GO-Pd the plot shows reduction of mass occurs from $20^{\circ} \mathrm{C}$ to $200^{\circ} \mathrm{C}$ due to the vaporisation of impure solvents which is remaining in the materials such as tert-Butanol having boiling point $83^{\circ} \mathrm{C}$, ethanol having boiling point $78.37^{\circ} \mathrm{C}$, acetone having boiling point $56^{\circ} \mathrm{C}$ and hydrogen peroxide having boiling point $150.2^{\circ} \mathrm{C}$. For hydrogenated GO-Pd nanocomposite the reduction of mass is more compared to GO-Pd nanocomposite in the temperature range $20^{\circ} \mathrm{C}$ to $200^{\circ} \mathrm{C}$. Here in hydrogenated GO-Pd the reduction of mass occurs at four different steps, 1) from $20^{\circ} \mathrm{C}$ to $150^{\circ} \mathrm{C}$ as shown. Most of the mass reduced due to the vaporisation of remaining solvents present in the composites such as ethanol, tert-Butanol, ethylene diamine, water, acetone, hydrogen peroxide and ammonia solution, 2) from $150^{\circ} \mathrm{C}$ to $200^{\circ} \mathrm{C}$ some mass reduction occurs which is also due to the remaining solvent which is adsorbed by palladium nanoparticles as shown in the Figure 13,3 ) from $200^{\circ} \mathrm{C}-350^{\circ} \mathrm{C}$ the weight reduction occurs due to the physically adsorbed hydrogen which is attached to the subsurface Pd atoms in the hydrogenated GO-Pd composites, this physically adsorbed hydrogen which is attached to Pd atoms with a weak Vander Waal's force is released when the temperature reaches above $200^{\circ} \mathrm{C}$, 4) from $350^{\circ} \mathrm{C}$ to $630^{\circ} \mathrm{C}$ the weight reduction occurs due to the chemisorption of hydrogen to the GO-Pd

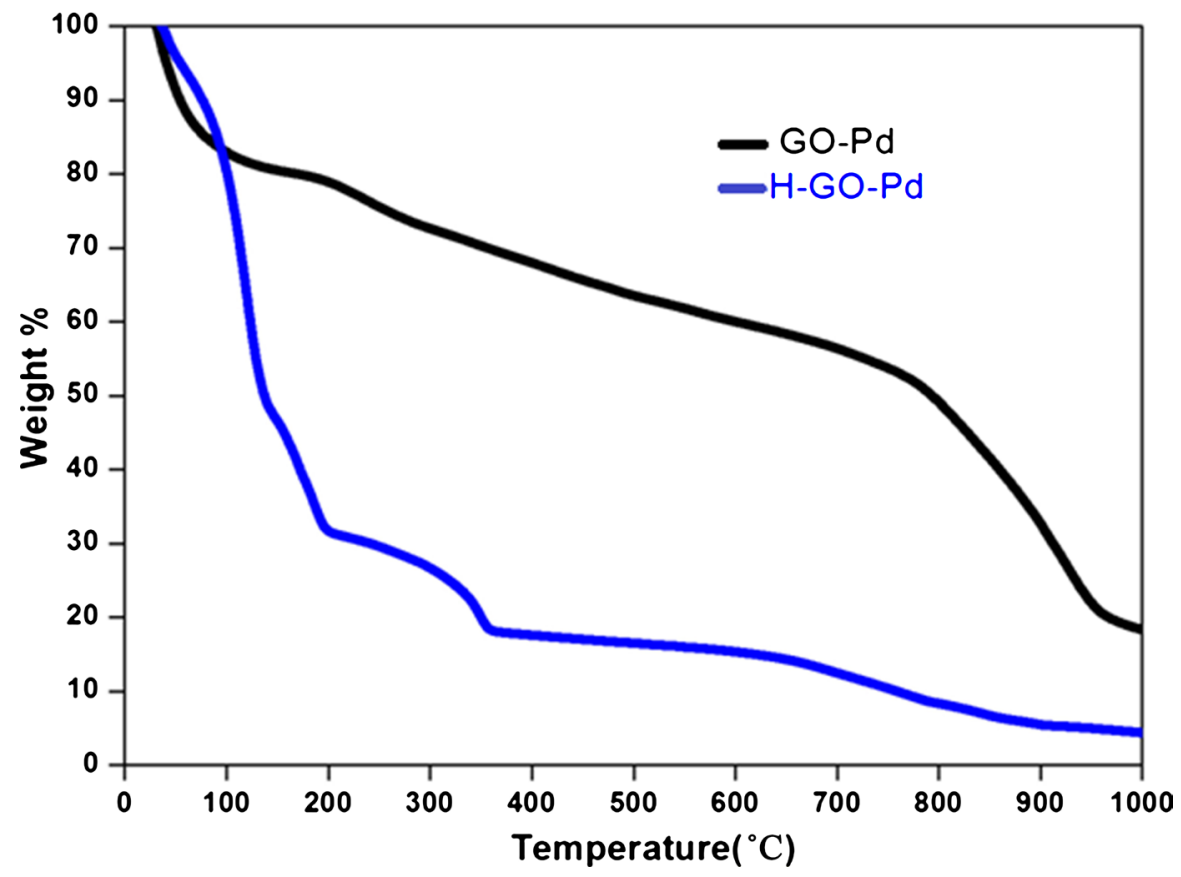

Figure 13. TGA analysis of the GO-Pd and H-GO-Pd nanocomposites. 
nanocomposites and here in this temperature range $\mathrm{C}-\mathrm{H}$ bond starts to break as the bond energy of $\mathrm{C}=\mathrm{C}$ stretching $(614 \mathrm{KJ} / \mathrm{mol})$ is more than $\mathrm{C}-\mathrm{H}$ stretching $(413 \mathrm{KJ} / \mathrm{mol}$ ), more energy (heat or temperature) is required to break the $\mathrm{C}=\mathrm{C}$ bond than $\mathrm{C}-\mathrm{H}$ bond [47]. After $630^{\circ} \mathrm{C}$ onwards $\mathrm{C}=\mathrm{C}$ bonds starts to break which is not necessary for our purpose.

For $\mathrm{H}-\mathrm{GO}-\mathrm{Pd}$ at $200^{\circ} \mathrm{C}$ weight loss is $68.25 \%$ and at $350^{\circ} \mathrm{C}$ weight loss is $81.48 \%$, this reduction of weight is the release of physically adsorbed hydrogen which is attached to the palladium surface by weak Vander wall's force. In between $350^{\circ} \mathrm{C}$ to $630^{\circ} \mathrm{C}$ the weight changes $18.52 \%$ to $14.4 \%$ and this reduction of weight is due to the release of hydrogen gas which occurs due to the breakage of $\mathrm{C}-\mathrm{H}$ covalent bond that is formed during the hydrogenation of GO-Pd nanocomposites.

From TGA analysis we have found that hydrogen is released in the temperature range of $200^{\circ} \mathrm{C}$ to $630^{\circ} \mathrm{C}$ in two phases. First phase is from $200^{\circ} \mathrm{C}-350^{\circ} \mathrm{C}$; which is due to the physiosorption. Second phase is from $350^{\circ} \mathrm{C}-630^{\circ} \mathrm{C}$; which is due to chemically adsorbed hydrogen. So the total amount of hydrogen stored in the nanocomposite is $17.35 \%$.

\subsection{Comparison Analysis}

Figure 14 shows a comparative analysis of hydrogen storage (wt \%) ability of GO-Pd composite estimated from the present study with the reported values of hydrogen storage in literatures. It is observed that hydrogenation of GO-Pd by employing Benkeser reaction results in considerably higher value of hydrogen storage $(17.35 \%)$ than the reported values of hydrogen storage on graphene using chemisorption and physiosorption processes. Maximum percent storage reported in the literature employing graphene oxide is 7.7\% [21] [27]. This study also reveals that the weight percent hydrogen, chemisorbed on GO-Pd through Benkeser reaction is almost 2.5 times than the weight percent hydrogen adsorbed on graphene oxide under the similar conditions.

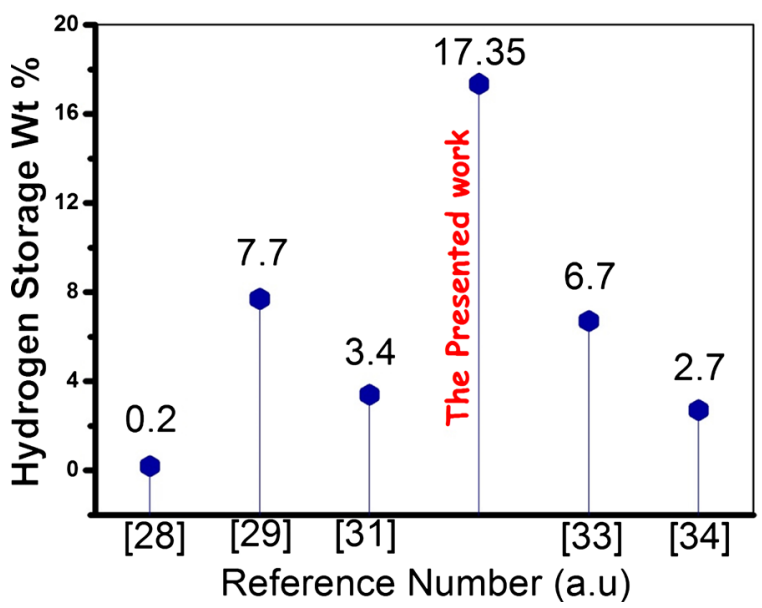

Figure 14. Hydrogen storage capacity of the present study vs the values reported in the literature. 


\section{Conclusion}

Graphene oxide palladium nanocomposites were hydrogenated by using lithium in ethylene diamine under Benkeser reaction at atmospheric pressure and room temperature. A moderate, possibly scalable way involving Benkeser reaction was employed to obtain chemically hydrogenated graphene oxide palladium nanocomposites. Benkeser reaction occurs at atmospheric pressure and normal temperature $\left(30^{\circ} \mathrm{C}\right)$ and avoids liquid ammonia temperature which is used in Birch reduction. Here due to presence of palladium nanoparticles physical adsorption of hydrogen takes place where due to Benkeser reaction chemisorbtion of hydrogen on graphene oxide surface occurs. From SEM image we can conclude that the uniform distribution of palladium particles over graphene surface occurs for adsorbing hydrogen. The FTIR analysis confirmed that hydrogen adsorption occurred at all the ortho, meta and para positions of aromatic graphene oxide palladium hydrogenation. The weight percent of hydrogen stored into prepared hydrogenated nanocomposite was estimated from comparative TG analysis of GO-Pd and hydrogenated GO-Pd. The weight percent of hydrogen which was stored during hydrogenation of graphene oxide palladium nanocomposites under Benkeser reaction by both physiosorption and chemisorption is equal to $17.35 \%$. This value is higher than the value which is reported in the literature.

\section{Conflicts of Interest}

The authors declare no conflicts of interest regarding the publication of this paper.

\section{References}

[1] Fan, Q.Y., Wang, H.Q., Song, Y.X., Zhang, W. and Yun, S.N. (2020) Five Carbon Allotropes from Squaroglitter Structures. Computational Materials Science, 178, Article ID: 109634. https://doi.org/10.1016/j.commatsci.2020.109634

[2] Wang, Z., Jin, J. and Sun, M. (2017) Effect of Boron (Nitrogen)-Divacancy Complex Defects on the Electronic Properties of Graphene Nanoribbon. Graphene, 6, 19-25. https://doi.org/10.4236/graphene.2017.61002

[3] Ariharan, A., Viswanathan, B. and Nandhakumar, V. (2017) Nitrogen Doped Graphene as Potential Material for Hydrogen Storage. Graphene, 6, 41-60. https://doi.org/10.4236/graphene.2017.62004

[4] Jarosz, A., Skoda, M., Dudek, I. and Szukiewicz, D. (2016) Oxidative Stress and Mitochondrial Activation as the Main Mechanisms Underlying Graphene Toxicity against Human Cancer Cells. Oxidative Medicine and Cellular Longevity, 2016, Article ID: 5851035. https://doi.org/10.1155/2016/5851035

[5] Nair, Asalatha, A.S., Sundara, R. and Anitha, N. (2015) Hydrogen Storage Performance of Palladium Nanoparticles Decorated Graphitic Carbon Nitride. International Journal of Hydrogen Energy, 40, 3259-3267. https://doi.org/10.1016/j.ijhydene.2014.12.065

[6] Nyangiwe, N., Khenfouch, M., Thema, F., Nukwa, K., Kotsedi, L. and Maaza, M. (2015) Free-Green Synthesis and Dynamics of Reduced Graphene Sheets via Sun 
Light Irradiation. Graphene, 4, 54-61. https://doi.org/10.4236/graphene.2015.43006

[7] Baitimbetova, B. and Vermenichev, B. (2015) New Method for Producing Graphene by Magnetron Discharge in an Atmosphere of Aromatic Hydrocarbons. Graphene, 4, 38-44. https://doi.org/10.4236/graphene.2015.42004

[8] Poh, C. and Shieh, H. (2016) Density Functional Based Tight Binding (DFTB) Study on the Thermal Evolution of Amorphous Carbon. Graphene, 5, 51-54. https://doi.org/10.4236/graphene.2016.52006

[9] Attia, N.F. and Geckeler, K.E. (2013) Polyaniline as a Material for Hydrogen Storage Applications. Macromolecular Rapid Communication, 34, 1043-1055. https://doi.org/10.1002/marc.201300255

[10] Schlapbach, L. and Züttel, A. (2001) Hydrogen-Storage Materials for Mobile Applications. Nature, 414, 353-358. https://doi.org/10.1038/35104634

[11] Wagemans, R.W.P., van Lenthe, J.H., de Jongh, P.E., Jos van Dillen, A. and de Jong, K.P. (2005) Hydrogen Storage in Magnesium Clusters: Quantum Chemical Study. Journal of the American Chemical Society, 127, 16675-16680. https://doi.org/10.1021/ja054569h

[12] Naik, G. and Krishnaswamy, S. (2017) Photoreduction and Thermal Properties of Graphene-Based Flexible Films. Graphene, 6, 27-40. https://doi.org/10.4236/graphene.2017.62003

[13] Radey, H., Al-Sawaad, H. and Khalaf, M. (2018) Synthesis and Characterization of Novel Nano Derivatives of Graphene Oxide. Graphene, 7, 17-29. https://doi.org/10.4236/graphene.2018.73003

[14] Lam, S., Sharma, N. and Kumar, L. (2017) Synthesis of Graphene Oxide (GO) by Modified Hummers Method and Its Thermal Reduction to Obtain Reduced Graphene Oxide (rGO)*. Graphene, 6, 1-18. https://doi.org/10.4236/graphene.2017.61001

[15] Basumallick, S. (2016) Amino-Functionalized Reduced Graphene-Oxide-Copper (I) Oxide Composite: A Prospective Catalyst for Photo-Reduction of $\mathrm{CO}_{2}$. Graphene, 5, 90-95. https://doi.org/10.4236/graphene.2016.52010

[16] Singh, P., Bahadur, J. and Pal, K. (2017) One-Step One Chemical Synthesis Process of Graphene from Rice Husk for Energy Storage Applications. Graphene, 6, 61-71. https://doi.org/10.4236/graphene.2017.63005

[17] Majumder, K., Barshilia, D. and Majee, S. (2018) Study on Graphene Based Next Generation Flexible Photodetector for Optical Communication. Graphene, 7, 9-16. https://doi.org/10.4236/graphene.2018.72002

[18] Dillon, A.C., Jones, K.M., Bekkedahl, T.A., Kiang, C.H., Bethhune, D.S. and Heben, M.J. (1997) Storage of Hydrogen in Single-Walled Carbon Nanotubes. Nature, 386, 377-379. https://doi.org/10.1038/386377a0

[19] Tang, X., Zhao, Y., Jiao, Q. and Cao, Y. (2010) Hydrogenation of Multiwall Carbon Nanotubes in Ethylenediamine. Nanotubes and Carbon Nanostructures, 18, 14-23. https://doi.org/10.1080/15363830903291697

[20] Stoller, M.D., Park, S., Zhu, Y., An, J. and Ruoff, R.S. (2008) Graphene Based Ultracapacitors. Nano Letters, 8, 3498-3502. https://doi.org/10.1021/nl802558y

[21] Sarkar, A.K., Saha, S., Ganguly, S., Banerjee, D. and Kargupta, K. (2014) Hydrogen Storage on Graphene Using Benkeser Reaction. International Journal of Energy Research, 38, 1889-1895. https://doi.org/10.1002/er.3203

[22] Park, S. and Ruoff, R.S. (2009) Chemical Methods for the Production of Graphenes. Nature, 4, 217-224. https://doi.org/10.1038/nnano.2009.58 
[23] López-Corral, I., Germán, E., Juan, A., Volpe, M.A. and Brizuela, G.P. (2011) DFT Study of Hydrogen Adsorption on Palladium Decorated Graphene. The Journal of Physical Chemistry C, 115, 4315-4323. https://doi.org/10.1021/jp110067w

[24] Eluyemi, M., Eleruja, M., Adedeji, A., Olofinjana, B., Fasakin, O., Akinwunmi, O., Ilori, O., Famojuro, A., Ayinde, S. and Ajayi, E. (2016) Synthesis and Characterization of Graphene Oxide and Reduced Graphene Oxide Thin Films Deposited by Spray Pyrolysis Method. Graphene, 5, 143-154. https://doi.org/10.4236/graphene.2016.53012

[25] Holt, R. and Rybolt, T. (2019) Modeling Enhanced Adsorption of Explosive Molecules on a Hydroxylated Graphene Pore. Graphene, 8, 1-18. https://doi.org/10.4236/graphene.2019.81001

[26] Konda, S.K. and Chen, A.C. (2015) One-Step Synthesis of Pd and Reduced Graphene Oxide Nanocomposites for Enhanced Hydrogen Sorption and Storage. Electrochemistry Communications, 60, 148-152. https://doi.org/10.1016/j.elecom.2015.08.023

[27] Cabria, I., López, M.J., Fraile, S. and Alonso, J.A. (2012) Adsorption and Dissociation of Molecular Hydrogen on Palladium Clusters Supported on Graphene. The Journal of Physical Chemistry C, 116, 21179-21189. https://doi.org/10.1021/jp305635w

[28] Pekker, S., Salvetat, J.P., Jakab, E., Bonard, J.M. and Forró, L. (2001) Hydrogenation of Carbon Nanotubes and Graphite in Liquid Ammonia. The Journal of Physical Chemistry B, 105, 7938-7943. https://doi.org/10.1021/jp010642o

[29] Pekker, S., Salvetat, J.P., Jakab, E., Bonard, J.M. and Forro, L. (2001) Hydrogenation of Carbon Nanotubes and Graphite in Liquid Ammonia. Journal of Physics Chemical Biology, 105, 7938-7943. https://doi.org/10.1021/jp0106420

[30] Greenfield, A. and Schindewolf, U. (1998) Kinetics of Birch Reduction. Journal of Physical Chemistry, 102, 1808-1814. https://doi.org/10.1002/bbpc.19981021211

[31] Bazhenov, A.V., Fursova, T.N., Bashkin, I.O., Antonov, V.E., Kondrateva, I.V., Krestinin, A.V. and Shulge, Y.M. (2006) Electronic and Vibration Spectra of Hydrogenated Carbon Single Walled Nanotubes and Fullerenes Nanotubes. Carbon Nanostructure, 14, 165-173. https://doi.org/10.1080/15363830600663487

[32] Wei, L. and Mao, Y.B. (2016) Enhanced Hydrogen Storage Performance of Reduced Graphene Oxide Hybrids with Nickel or Its Metallic Mixtures Based on Spillover Mechanism. International Journal of Hydrogen Energy, 41, 11692-11699. https://doi.org/10.1016/j.ijhydene.2016.04.030

[33] Pyle, D.S., Mac, E., Gray, A. and Webb, C.J. (2016) Hydrogen Storage in Carbon Nanostructures via Spillover. International Journal of Hydrogen Energy, 41, 19098-19113. https://doi.org/10.1016/j.ijhydene.2016.08.061

[34] Kishore, S., Nelson, J.A., Adair, J.H. and Eklund, P.C. (2005) Hydrogen Storage in Spherical and Platelet Palladium Nanoparticles. Journal of Alloys and Compounds, 389, 234-242. https://doi.org/10.1016/j.jallcom.2004.06.105

[35] Zielinska, B., Michalkiewicz, B., Mijowska, E. and Kalenczuk, R.J. (2015) Advances in Pd Nanoparticle Size Decoration of Mesoporous Carbon Spheres for Energy Application. Nanoscale Research Letters, 10, Article No. 430. https://doi.org/10.1186/s11671-015-1113-y

[36] Li, G., Kobayashi, H., Taylor, J., et al. (2014) Hydrogen Storage in Pd Nanocrystals Covered with a Metal-Organic Framework. Nature Materials, 13, 802-806. https://doi.org/10.1038/nmat4030

[37] Saha, S., Mitra, M., Sarkar, A., Banerjee, D., Ganguly, S. and Kargupta, K. (2018) 
Lithium Assisted Enhanced Hydrogen of Reduced Graphene Oxide-PANI Nanocomposite at Room Temperature. Diamond and Related Materials, 84, 103-111. https://doi.org/10.1016/j.diamond.2018.03.012

[38] Benkeser, R.A., Robinson, R.E., Sauve, D.M. and Thomas, O.H. (1954) Selective Reduction of Aromatic System of Monoolefins. Journal of American Chemical Society, 76, 631-632. https://doi.org/10.1021/ja01631a106

[39] Benkeser, R.A., Arnold, C.J., Lambert, R.F. and Owen, T.H. (1955) Reduction of Organic Compounds by Lithium in Low Molecular Amines and Reduction of Aromatic Compounds Containing Functional Groups. Journal of American Chemical Society, 77, 6042-6045. https://doi.org/10.1021/ja01627a071

[40] Tang, X.L., Zhao, Y., Jiao, Q.Z. and Cao, Y. (2010) Hydrogenation of Multi-Walled Carbon Nanotubes in Ethylenediamine. Fullerenes Nanotubes and Carbon Nanostructures, 18, 14-23. https://doi.org/10.1080/15363830903291697

[41] Dostert, K.-H., et al. (2016) Adsorption of Acrolein, Propanal, and Allyl Alcohol on Pd(111): A Combined Infrared Reflection-Absorption Spectroscopy and Temperature Programmed Desorption Study. Physical Chemistry Chemical Physics, 18, 13960-13973. https://doi.org/10.1039/C6CP00877A

[42] Ignat, M., Sacarescu, L., Cool, P. and Harabagiu, V. (2015) Glycerol-Derived Mesoporous Carbon: N2-Sorption and SAXS Data Evaluation. Materials Today. Proceedings, 2, 3836-3845. https://doi.org/10.1016/j.matpr.2015.08.012

[43] Olumurewa, K., Olofinjana, B., Fasakin, O., Eleruja, M. and Ajayi, E. (2017) Characterization of High Yield Graphene Oxide Synthesized by Simplified Hummers Method. Graphene, 6, 85-98. https://doi.org/10.4236/graphene.2017.64007

[44] Narayana, M. and Jammalamadaka, S. (2016) Tuning Optical Properties of Graphene Oxide under Compressive Strain Using Wet Ball Milling Method. Graphene, 5, 73-80. https://doi.org/10.4236/graphene.2016.52008

[45] Ansón, A., Lafuente, E., Urriolabeitia, E., Navarro, R., Benito, A.M., Maser, W.K. and Martínez, M.T. (2006) Hydrogen Capacity of Palladium-Loaded Carbon Materials. The Journal of Physical Chemistry B, 110, 6643-6648. https://doi.org/10.1021/jp057206c

[46] Zhou, C.Y. and Szpunar, J.A. (2016) Hydrogen Storage Performance in Pd/Graphene Nanocomposites. ACS Applied Materials \& Interfaces, 8, 25933-25940. https://doi.org/10.1021/acsami.6b07122

[47] Taher, F., Moursy, N.S., Aman, D., Attia, S.Y. and Mohamed, S.G. (2020) Synthesis and Evaluation of Materials for High-Performance Supercapacitators. Interceram International Ceramic Review, 69, 30-37.

https://doi.org/10.1007/s42411-020-0080-1 